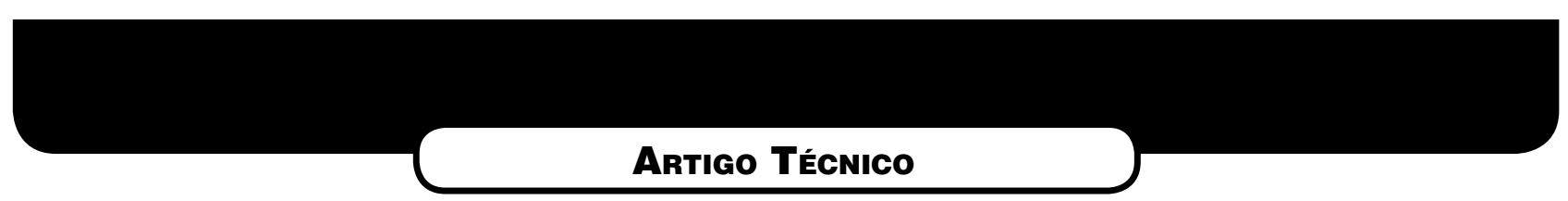

\title{
ReCICLAGEM DE LOdO DE ESGOTO EM PLANTAÇÃO DE EUCALIPTO: CARBONO E NITROGÊNIO
}

\section{SEWAGE SLUDGE RECYCLING IN EUCALYPT PLANTATION: CARBON AND NITROGEN}

\begin{abstract}
ANA CLÁUdia SILVA DE LIRA
Engenheira Agrônoma. Doutora em Ciências da Engenharia Ambiental. Professora da Universidade do Estado do Amapá

\section{MarCELINo CARNEIRo Guedes}

Engenheiro Florestal. Doutor em Recursos Florestais. Pesquisador da Embrapa Amapá
\end{abstract}

\section{VALDIR SCHALCH}

Engenheiro Químico. Professor Livre-Docente do Departamento de Hidráulica e Saneamento da Escola de Engenharia de São Carlos - USP

Recebido: 28/07/06 Aceito: 28/04/08

\section{RESUMO}

O objetivo geral do trabalho desenvolvido foi avaliar como o lodo de esgoto (biossólido) altera os estoques de $\mathrm{C}$ e $\mathrm{N}$ em plantação de eucalipto. $\mathrm{O}$ estudo foi conduzido com aplicação de doses até $40 \mathrm{t} \mathrm{ha}^{-1}$ de biossólido, em base seca, para cultivo de Eucalyptus grandis. Os eucaliptos que receberam $10 \mathrm{t} \mathrm{ha}^{-1}$ de biossólido apresentaram igual desenvolvimento aos que receberam adubação mineral completa, produzindo, em média, 107,5 t ha ${ }^{-1}$ de biomassa acima do solo, 63\% a mais do que a testemunha. Esses tratamentos apresentaram também maiores valores de conteúdo de $\mathrm{C}$ e $\mathrm{N}$ na biomassa. $\mathrm{O}$ biossólido tratado com cal, aplicado em superfície, apresentou baixas taxas de decomposição e não contribuiu para aumentar os estoques totais de $\mathrm{C}$ e $\mathrm{N}$ no solo. $\mathrm{O}$ efeito do resíduo sobre o desenvolvimento das árvores é mais importante para fornecer entradas de material orgânico no sistema do que sua própria aplicação.

PALAVRAS-CHAVES: Biossólido, Eucalyptus grandis, nutrientes, seqüestro de C

\begin{abstract}
The general aim of this research was to evaluate as the sewage sludge (biosolids) modify $C$ and $N$ stocks in eucalypt plantation. The study was installed with application rates up to $40 \mathrm{th}^{-1}$ of $d r y$ matter biosolids in Eucalyptus grandis plantation. The eucalypts that received $10 \mathrm{th}^{-1}$ of biosolids presented even development that it received full mineral fertilizer, producing, on average, 107,5 tha - $^{-1}$ aboveground biomass, 63\% the more than control. Those treatments also presented larger values of $C$ and $N$ contents in the biomass. The biosolids treated with lime, applied in surface, showed low decomposition rates and it didn't contribute to increase $C$ and $N$ soil total stocks. The effect of residue on the development of trees is more important to supply input of organic material in system than own application.
\end{abstract}

\section{INTRODUÇÃO}

A dificuldade para realizar a disposição final adequada do lodo de esgoto produzido nas estaçōes de tratamento é um problema para os gerentes da área de saneamento no Brasil. No passado, a maior preocupação era com o desenvolvimento e adequação dos processos de tratamento da fase líquida. O lodo era amontoado em áreas das próprias estações, levado para aterros e lixões e até mesmo devolvido aos próprios cursos de água. Atualmente, vem crescendo a atenção com a disposição final do lodo e várias alternativas estão sendo testa- das em território nacional. De acordo com Tsutya (2000), o tratamento e a disposição final do lodo representam de $20 \%$ a $40 \%$ das despesas operacionais de uma ETE. Dentre as alternativas existentes, acredita-se que a reciclagem do lodo como biossólido em plantaçōes florestais é uma das mais interessantes.

O lodo de esgoto devidamente tratado, que vem sendo utilizado como fertilizante e condicionador de solo por ser rico em nutrientes e matéria orgânica, é chamado de biossólido. Pesquisas vêm demonstrando que esse resíduo pode ser reutilizado para fins agrícolas e/ou florestais, evitando sua deposição em aterros e lixões, geralmente localizados na periferia das grandes cidades. Assim, esse resíduo, hoje problemático, no futuro poderá ser considerado um insumo, gerando um estímulo para que mais esgotos urbanos sejam tratados antes de promoverem a eutrofização e poluição dos rios.

No exterior, as pesquisas sobre o uso do lodo de esgoto como biossólido em áreas agrícolas e florestais estão bastante desenvolvidas, principalmente, em alguns países da América do Norte e Europa. Vários países, como a Alemanha, já utilizam em escala operacional a destinação de grande parte ou 
de todo o lodo gerado às plantaçôes florestais. No entanto, mesmo em caráter experimental, pouco se conhece sobre os efeitos da aplicação de biossólido na ciclagem do $\mathrm{C}$ e do $\mathrm{N}$ e na imobilização desses elementos nos compartimentos do ecossistema.

A pesquisa que gerou este artigo foi baseada na hipótese de que a aplicação do lodo de esgoto tratado (biossólido) modifica aspectos do ciclo do $\mathrm{C}$ e $\mathrm{N}$ em ecossistema com cultivo de eucalipto, exercendo efeitos sobre processos como a utilização e imobilização de nutrientes nos compartimentos do sistema. Sendo assim, o objetivo do estudo foi avaliar o efeito da utilização do biossólido sobre os estoques de $\mathrm{C} \mathrm{e}$ $\mathrm{N}$ nos eucaliptos, na serapilheira, no solo e no biossólido remanescente após cinco anos de aplicação.

\section{METODOLOGIA}

O presente estudo foi conduzido na Estação Experimental de Itatinga, vinculada ao Departamento de Ciências Florestais da Escola Superior de Agricultura "Luiz de Queiroz", localizada no município de Itatinga - SP.

O solo da área experimental foi classificado como Latossolo VermelhoAmarelo, com textura médio-arenosa, relevo suavemente ondulado. Apresenta baixos teores de nutrientes (Tabela 1). Esse tipo de solo é um dos mais representativos das áreas onde, hoje, é praticada a silvicultura de eucalipto no estado de São Paulo.
O tipo de solo em questão é naturalmente muito intemperizado e pouco fértil, por isso observam-se valores extremamente baixos de $\mathrm{P}$ disponível, de $\mathrm{K}$, Ca e $\mathrm{Mg}$ trocáveis, além de elevada saturação por Al e baixo $\mathrm{pH}$. Um outro fato que pode explicar essa baixa disponibilidade de nutrientes é que na área foram conduzidas, por aproximadamente cinqüenta anos, seguidas rotaçôes de Eucalyptus saligna sem qualquer reposição dos nutrientes via adubação.

De acordo com a classificação de Köeppen, o clima do local é do tipo mesotérmico úmido, com precipitação média mensal do mês mais seco entre 30 e $60 \mathrm{~mm}$. A temperatura mínima anual é de $12,8^{\circ} \mathrm{C}$ e média anual de $19,4^{\circ} \mathrm{C}$. A umidade relativa média anual é de $83,3 \%$, e a precipitação média anual é de $1635 \mathrm{~mm}$. O balanço hídrico apresenta um excedente de $762 \mathrm{~mm}$, e déficit de $3 \mathrm{~mm}$ nos meses de julho e agosto, com uma evapotranspiração potencial de $877 \mathrm{~mm}$, e capacidade de armazenamento do solo de $150 \mathrm{~mm}$.

A vegetação natural da regiāo é o cerrado, sendo que a maior parte da estação era ocupada por cerrado sensu stricto. Atualmente, existem algumas manchas desse tipo de vegetação, mas predominam culturas florestais de eucaliptos e pinheiros.

O biossólido utilizado neste experimento foi proveniente da ETE de Barueri, região metropolitana de São Paulo. A caracterização físico-química e manutenção da qualidade do bios- sólido foram de responsabilidade da SABESP. Para isso, a mesma levou em consideração o estabelecido pela norma norte-americana 40 CFR Part 503, elaborada pela Agência de Proteção Ambiental dos Estados Unidos (EPA, 1984) e pela norma do Estado de São Paulo (CETESB, 1999).

$\mathrm{Na}$ ETE, o esgoto passou por um tratamento biológico, que consiste na digestão aeróbia utilizando ar difuso durante a fase de decantação, e digestão anaeróbia dos lodos primários e secundários. Após isso houve o condicionamento químico com cal $\left(\mathrm{Ca}(\mathrm{OH})_{2}\right)$ e cloreto férrico $\left(\mathrm{FeCl}_{3}\right)$ e desidratação na fase final, deixando o resíduo (biossólido) com, aproximadamente, 60\% de umidade.

A densidade de coliformes fecais no resíduo utilizado foi inferior a $2 \times 10^{6} \mathrm{NMP} \mathrm{g} \mathrm{ST}^{-1}$ (Número Mais Provável por grama de Sólidos Totais), sendo caracterizado como biossólido tipo B (CETESB, 1999); já que o processo de estabilização com cal é aceito pelo órgão controlador como eficiente na redução de patógenos e a densidade dos organismos indicadores ficou abaixo do limite permitido.

Em julho de 1998, o biossólido foi aplicado a lanço, em cobertura, entre as linhas de plantio (faixa de 2 metros), deixando, aproximadamente, meio metro de distância das mudas. A composição do biossólido usado é mostrada na Tabela 2 .

Tabela I - Atributos químicos e físicos do solo da área experimental, em diversas profundidades (Pf), antes da aplicação do biossólido

\begin{tabular}{|c|c|c|c|c|c|c|c|c|c|c|c|c|}
\hline $\begin{array}{l}\mathrm{Pf} \\
\mathrm{cm}\end{array}$ & $\begin{array}{c}\mathrm{pH} \\
\mathrm{CaCl}_{2}\end{array}$ & $\begin{array}{l}\text { M.O. } \\
\mathrm{g} \mathrm{dm}^{-3}\end{array}$ & $\begin{array}{c}{ }^{*} \mathrm{P} \\
\mathrm{mg} \mathrm{dm^{-3 }}\end{array}$ & K & $\mathrm{Ca}$ & $\mathrm{Mg}$ & $\begin{array}{l}\mathrm{H}+\mathrm{Al} \\
\mathrm{mol}_{\mathrm{c}} \mathrm{dn}\end{array}$ & - & SB & $\mathrm{T}$ & $\begin{array}{l}\mathrm{V} \\
\%\end{array}$ & $\begin{array}{c}\text { Sat. Al } \\
\%\end{array}$ \\
\hline $0-5$ & 3,4 & 47 & 4 & 0,9 & 1 & 1 & 128 & 24 & 3 & 131 & 2 & 89 \\
\hline $5-10$ & 3,7 & 21 & 5 & 0,2 & 1 & 1 & 68 & 15 & 2 & 70 & 3 & 87 \\
\hline $10-20$ & 3,8 & 17 & 4 & 0,2 & 1 & 1 & 58 & 12 & 2 & 60 & 4 & 84 \\
\hline $20-40$ & 3,9 & 14 & 3 & 0,2 & 2 & 1 & 47 & 8 & 3 & 50 & 6 & 71 \\
\hline $\mathrm{Pf}$ & $\mathrm{Cu}$ & $\mathrm{Zn}$ & $\mathrm{Mn}$ & $\mathrm{Fe}$ & $S$ & B & Areia & Silte & Argila & \multicolumn{2}{|c|}{ D A } & D R \\
\hline $\mathrm{cm}$ & & 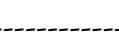 & -----mg dn & - & -.-.- & & & $-\ldots \%-$ & & \multicolumn{3}{|c|}{--.---g cm ${ }^{-3}$} \\
\hline $0-5$ & 1,0 & 1,4 & 1,8 & 87 & 5 & 0,07 & 88 & 4 & 8 & \multicolumn{2}{|c|}{1,25} & 2,30 \\
\hline $5-10$ & 1,4 & 0,6 & 0,8 & 76 & 7 & 0,06 & 85 & 5 & 10 & \multicolumn{2}{|c|}{1,26} & 2,30 \\
\hline $10-20$ & 1,0 & 0,8 & 0,4 & 68 & 10 & 0,07 & 85 & 5 & 10 & \multicolumn{2}{|c|}{1,21} & 2,30 \\
\hline $20-40$ & 1,2 & 0,4 & 0,4 & 55 & 13 & 0,06 & 85 & 5 & 10 & \multicolumn{2}{|c|}{1,30} & 2,33 \\
\hline
\end{tabular}


Tabela 2 - Composição do biossólido tratado com cal. Valores totais expressos em base seca

\begin{tabular}{cccccccc}
\hline $\mathrm{N}$ & $\mathrm{P}$ & $\mathrm{K}$ & $\mathrm{C} . \mathrm{O}$. & $\mathrm{Ca}$ & $\mathrm{Mg}$ & $\mathrm{SO}_{4}^{-}$ & $\begin{array}{c}\mathrm{pH} \\
\left(\mathrm{em} \mathrm{CaCl}_{2}\right)\end{array}$ \\
\hline 19 & 9 & 2 & 172 & 86 & 4 & 7 & 10,6 \\
$\mathrm{Fe}$ & $\mathrm{Cu}$ & $\mathrm{Mn}$ & $\mathrm{Zn}$ & $\mathrm{Cd}$ & $\mathrm{Cr}$ & $\mathrm{Ni}$ & $\mathrm{Pb}$ \\
-056 & 900 & 258 & 1632 & - & 258 & 222 & 82 \\
\hline
\end{tabular}

- não detectado; C. O: Carbono Orgânico

O experimento foi implantado em quatro blocos casualizados, definidos em função da declividade da área. Foram aplicados 5 tratamentos com 4 repetições, totalizando 20 parcelas. Cada parcela possui $600 \mathrm{~m}^{2}(30 \times 20)$ e foi constituída por 10 linhas de $20 \mathrm{~m}$ de comprimento cada. $\mathrm{Na}$ linha as plantas foram espaçadas em $2 \mathrm{~m}$ e nas entrelinhas em $3 \mathrm{~m}$, totalizando 100 plantas por parcela. A posição das parcelas dentro de cada bloco foi definida por sorteio. A área útil da parcela considerou as 36 plantas centrais, descontando-se a bordadura dupla. foram:

Os cinco tratamentos avaliados

1) testemunha absoluta, sem adubação e sem aplicação de biossólido (T);

2) adubação mineral (Ad);

3) $10 \mathrm{t} \mathrm{ha}^{-1}$ de biossólido complementado com K e P no plantio $(10+K P)$;

4) $20 \mathrm{t} \mathrm{ha}^{-1}$ de biossólido complementado com $\mathrm{K}(\mathbf{2 0 + K})$ e

5) $40 \mathrm{t} \mathrm{ha}^{-1}$ de biossólido complementado com $\mathrm{K}(\mathbf{4 0}+\mathbf{K})$.

As doses de biossólido foram calculadas em base seca. No entanto, o material foi aplicado úmido. A dose máxima de biossólido aplicada, $40 \mathrm{t} \mathrm{ha}^{-1}$, foi definida em função do seu elevado teor de $\mathrm{Ca}$, resultante do processo de tratamento do esgoto, que poderia causar desequilíbrios nutricionais. Outros fatores, como teor e taxa de mineralização do $\mathrm{N}$ e teores de metais pesados, também foram considerados na determinação das doses aplicadas.

A adubação mineral no tratamento Ad foi realizada conforme descrito por Vaz (2000). A complementação com $\mathrm{K}$ mineral (KCl, $60 \%$ de $\mathrm{K}_{2} \mathrm{O}$ ) foi necessária em todos os tratamentos onde foi aplicado biossólido, porque o teor desse elemento no resíduo é baixo, assim como no solo da área experimental.
O sistema de amostragem seguiu delineamento sistemático durante a realização das coletas das amostras, que foram sempre realizadas dentro da área útil das parcelas.

Durante todo o período experimental foram registrados, diariamente, dados pluviométricos e as temperaturas máximas e mínimas do ar através de instrumentos de uma estação meteorológica, situada na própria Estação Experimental.

\section{Estoque de $\mathbf{C}$ e $\mathbf{N}$ na biomassa florestal}

Para determinar a biomassa e o conteúdo de $\mathrm{C}$ e $\mathrm{N}$ em cada componente das árvores, foram abatidas duas árvores por parcela, em março de 2003, quando as árvores completaram cinco anos de idade. Foram abatidas oito árvores por tratamento, totalizando quarenta indivíduos. A biomassa do lenho e casca foi determinada por cubagem rigorosa das árvores abatidas, calculando-se os volumes com e sem casca, e a densidade básica (método da balança hidrostática) desses componentes. Foram coletados discos com casca da base da árvore e a 25\%, 50\%, 75\% e $100 \%$ da altura comercial, além de mais um disco na altura do DAP. Todas as folhas e os galhos de cada árvore foram separados e pesados no campo. Foram retiradas amostras que também foram pesadas no campo e levadas ao laboratório para obter seu peso seco e realização das análises químicas.

A mineralomassa de $\mathrm{C}$ e $\mathrm{N}$ de cada componente das árvores foi calculada multiplicando-se a biomassa, estimada por equaçôes alométricas aplicadas em todas as árvores da área útil de cada parcela, pelo respectivo teor de cada nutriente analisado nas amostras da parcela.

As análises químicas de material vegetal foram realizadas após o material ser seco a $65^{\circ} \mathrm{C}$ em estufas de ventilação forçada até peso constante, e trituração em moinho tipo Wiley (peneira de 20 mesh $=0,8 \mathrm{~mm}$ ). O C foi determinado por oxidação via úmida e o $\mathrm{N}$ foi determinado por titulação após digestão em micro-Kjeldhal.

\section{Estoques de $\mathbf{C}$ e $\mathbf{N}$ na serapilheira e no biossólido remanescente}

A serapilheira acumulada sobre o solo (manta florestal) foi determinada utilizando moldura de $0,25 \mathrm{~m}^{2}(0,5 \times 0,5 \mathrm{~m})$. Foram coletadas, nas entre-linhas de plantio, três amostras por parcela, totalizando doze repetiçôes por tratamento para a variável biomassa. As três amostras de cada parcela foram processadas juntas para compor uma amostra para realizar a determinação química dos nutrientes.

A coleta do biossólido foi realizada seguindo a diagonal da área útil das parcelas, sendo coletadas três amostras em cada uma, totalizando dozerepetições por tratamento. Cada amostra foi coletada em área de $0,25 \mathrm{~m}^{2}(0,5 \times 0,5 \mathrm{~m})$, com o auxílio de um gabarito, de uma pequena pá e de duas peneiras (malhas de $2 \mathrm{~mm}$ e $1 \mathrm{~mm}$, separando o biossólido em duas fraçóes (a: $>2 \mathrm{~mm}$; b: $>1$ e $\leq 2 \mathrm{~mm}$ ). Antes da coleta, a área foi limpa manualmente, retirando-se, cuidadosamente, a serapilheira e a vegetação de sub-bosque que existiam no local. As análises do biossólido foram realizadas após secagem a $40{ }^{\circ} \mathrm{C}$ em estufas de ventilação forçada até peso constante e moagem do material em cadinho com pistilo. As determinaçóes dos teores totais dos nutrientes foram realizadas no Laboratório de Química Ambiental do Departamento de Química Ambiental da ESALQ, após digestão Kjeldhal para $\mathrm{N}$ e combustão via seca para o $\mathrm{C}$.

\section{Estoque de $\mathbf{C}$ e $\mathbf{N}$ no solo}

Foram coletadas cinco amostras de terra nas entrelinhas de cada parcela, nas profundidades de 0-10, 10-20, 20-30 e 30-60 cm, para compor uma amostra por profundidade por parcela. Foram coletadas duas amostras indeformadas para análise da densidade, no meio das mesmas profundidades anteriores, dentro da área útil da parcela.

As análises da terra coletada foram realizadas após secagem a $40{ }^{\circ} \mathrm{C}$ em estufas de ventilação forçada até 
peso constante e peneiramento em malha de $2 \mathrm{~mm}$ (9 mesh). Os teores totais de $\mathrm{C}$ e $\mathrm{N}$ foram determinados em equipamento auto-analisador Leco após reprocessamento das amostras em almofariz até se atingir granulometria com textura de pó (100 mesh). Foram também determinados teores de $\mathrm{C}$ pelo método de Walkley e Black modificado (Andrade, 2004). Os teores de $\mathrm{N}$ mineral $\left(\mathrm{NO}^{-3} \mathrm{e} \mathrm{NH}^{+4}\right)$ foram determinados de acordo com Mulvaney (1996).

\section{Análise dos dados}

As variáveis respostas referentes ao conteúdo de nutrientes nos componentes das árvores, assim como a biomassa, foram analisadas através da Análise de Variância. As comparações entre as médias foram realizadas através dos Intervalos de Confiança construídos com 95\% de certeza.

Para estimativa da biomassa das árvores foram utilizadas equações alométricas de um modelo exponencial, derivadas de funções de variação selecionadas e ajustadas por Guedes (2005), através da cubagem rigorosa das árvores, aos cinco anos de idade.

\section{RESULTADOS}

\section{Estoque de $\mathbf{C}$ e $\mathbf{N}$ na biomassa aérea}

A análise estatística da biomassa epígea do eucalipto mostrou que essa variável foi significativamente $(\mathrm{F}=5,0665 ; \mathrm{p}=0,0126)$ afetada pelos tratamentos. Verifica-se através da análise dos intervalos de confiança (Figura 1) que houve diferenças significativas dos eucaliptos do tratamento $\mathbf{A D}$ e $\mathbf{1 0 + K P}$ em relação aos tratamentos $\mathbf{T}$ e $\mathbf{2 0 + K}$. O tratamento 10+KP foi suficiente para que os eucaliptos produzissem a mesma quantidade de matéria seca epígea que os eucaliptos do tratamento AD.

Considerando a biomassa total acima do solo, as árvores de eucalipto dos tratamentos 10+KP e AD produziram, em média, 107,5 $\mathrm{t} \mathrm{ha}^{-1}$. Esse valor é $63 \%$ superior ao valor médio encontrado nas árvores testemunhas.

O compartimento lenho representou, aproximadamente, $75 \%$ da biomassa aérea dos eucaliptos em todos os tratamentos. As árvores do tratamento $10+\mathrm{KP}$ acumularam, em média, mais biomassa em todos os componentes, tanto nos troncos quanto nas copas.
Para as árvores desse tratamento, que apresentaram maior produtividade, a biomassa total de tronco (lenho + casca) acumulada em cinco anos foi de 94,9 t ha ${ }^{-1}$, o que resultou em um incremento médio anual (IMA) de $19 \mathrm{t} \mathrm{ha}^{-1}$ ano $^{-1}$ de madeira com casca.

A análise estatística dos estoques de C e N na biomassa total de eucalipto acima do solo mostrou efeitos significativos para ambos os elementos. No caso do C total estocado nas árvores, a variação em função dos tratamentos seguiu o que foi observado para a biomassa total. Os eucaliptos dos tratamentos $\mathbf{A D}$ e 10+KP apresentaram diferenças significativas em relação aos tratamentos $\mathbf{T}$ e $\mathbf{4 0}+\mathbf{K}$ (Figura 2).

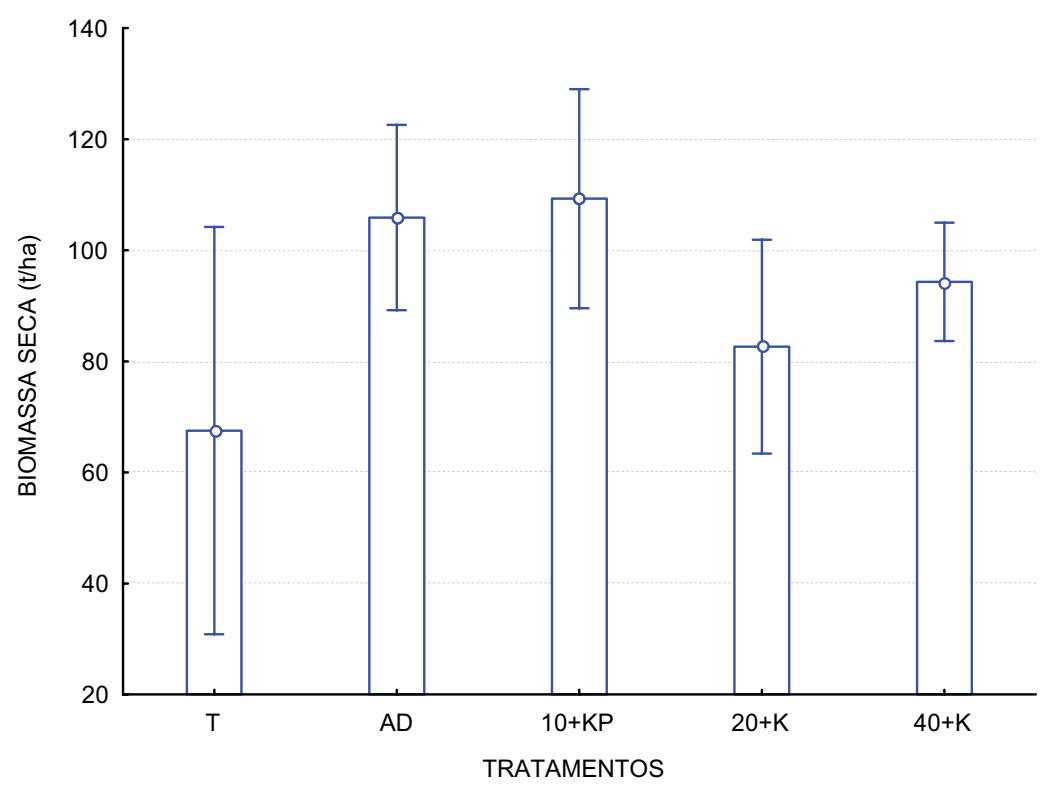

Figura I - Efeito dos tratamentos sobre a biomassa epígea de Eucalyptus grandis aos cinco anos de idade. A variação em torno da média $(n=4)$ é o intervalo de confiança construído com $95 \%$ de certeza

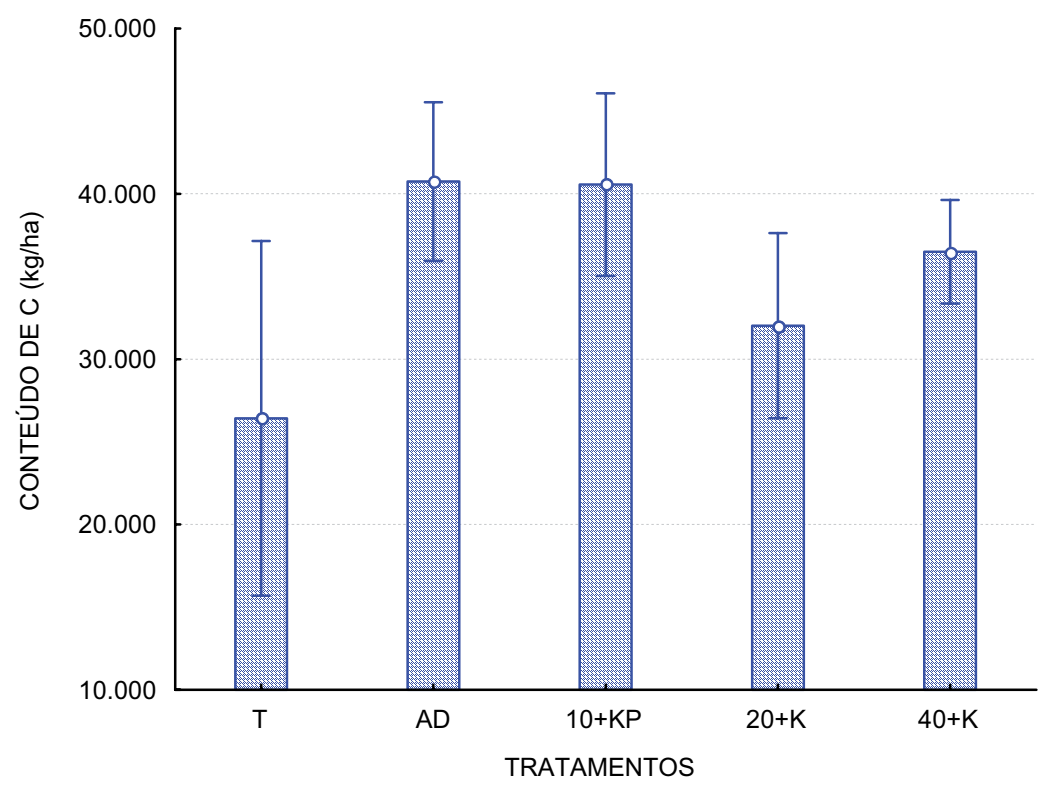

Figura 2 - Efeito dos tratamentos sobre o conteúdo de Carbono na biomassa epígea de Eucalyptus grandis aos cinco anos de idade. A variação em torno da média $(n=4)$ é o intervalo de confiança construído com $95 \%$ de certeza 
$\mathrm{Na}$ Figura 3 verifica-se que, em média, todos os tratamentos apresentaram maiores quantidades de $\mathrm{N}$ estocado na bioamassa epígea dos eucaliptos quando comparados com o tratamento testemunha ( $\left.383 \mathrm{~kg} \mathrm{ha}^{-1}\right)$. No entanto, as diferenças só foram significativas em relação aos tratamentos $\mathbf{1 0 + K P}$ e $\mathbf{A D}$. Não houve diferenças significativas entre os tratamentos que receberam biossólido e o $\mathbf{A D}$, cujo valor médio foi igual a $648 \mathrm{~kg} \mathrm{ha}^{-1}$.

Os tratamentos não influenciaram de maneira significativa a proporção de imobilização de biomassa e dos conteúdos de $\mathrm{C}$ e $\mathrm{N}$ entre os componentes do tronco (lenho + casca) e os componentes da copa (galhos + folhas). A análise estatística dos índices gerados pela relação tronco/copa mostrou ausência de significância tanto para a biomassa seca $(\mathrm{F}=0,5800$; $\mathrm{p}=0,6827)$, quanto para os conteúdos de $\mathrm{N}(\mathrm{F}=1,8973 ; \mathrm{p}=0,175686)$ e de $\mathrm{C}$ $(\mathrm{F}=0,4320 ; \mathrm{p}=0,7829)$.

\section{Estoque de $\mathbf{C}$ e $\mathbf{N}$ na serapilheira}

$\mathrm{Na}$ Tabela 3 são apresentados os valores da biomassa de serapilheira que constituía a manta florestal sobre o solo e o estoque de $\mathrm{C}$ e $\mathrm{N}$ armazenados nessa serapilheira, cinco anos após o plantio dos eucaliptos. A análise da significância das diferenças entre os tratamentos resultou em valores de $\mathrm{F}=2,7650$ e $\mathrm{p}=0,0770$ para a biomassa da serapilheira, $F=2,1650$ e $p=0,1349$ para o conteúdo de $\mathrm{C}$ estocado na serapilheira e $F=6,7550$ e $p=0,0044$ para o conteúdo de $\mathrm{N}$. Observa-se que a variação entre os tratamentos menos significativa foi para o conteúdo de $\mathrm{C}$, variável essa com diferenças significativas a um nível de $13 \%$ de probabilidade. Considerando a elevada variação natural dessas medições quando do trabalho de campo, esse é um nível de erro aceitável para se realizar a análise e a discussão estatística.

Observa-se que nas parcelas dos tratamentos $\mathbf{A D}$ e 10+KP foi acumulada maior quantidade de serapilheira. Esses tratamentos foram os que apresentaram também os maiores valores de biomassa (tabela 5). Já as parcelas do tratamento $\mathbf{T}$ apresentaram menor quantidade de serapilheira acumulada, refletindo assim a ausência dos nutrientes que entraram no sistema via adubação mineral e biossólido.

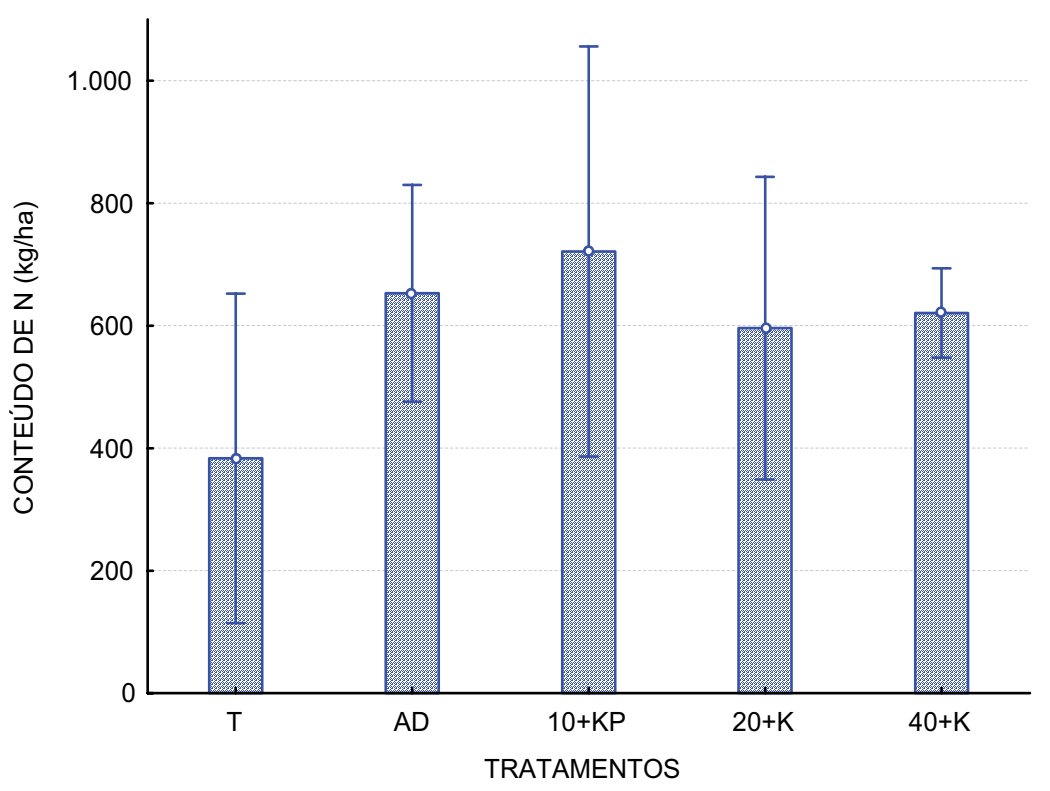

Figura 3 - Efeito dos tratamentos sobre o conteúdo de Nitrogênio na biomassa epígea de Eucalyptus grandis aos cinco anos de idade. A variação em torno da média $(n=4)$ é o intervalo de confiança construído com $95 \%$ de certeza

Tabela 3 - Valores médios $(\mathrm{n}=12)$ de biomassa seca, do conteúdo de C e N em serapilheira acumulada sobre o solo em cada tratamento, cinco anos após o plantio dos eucaliptos

\begin{tabular}{cccc}
\hline Tratamento & $\begin{array}{c}\text { Serapilheira } \\
\text { t ha-1 }\end{array}$ & $\begin{array}{c}\mathrm{C} \\
\text { kg ha-1 }\end{array}$ & $\begin{array}{c}\mathrm{N} \\
\mathrm{kg} \mathrm{ha}-1\end{array}$ \\
\hline $\mathrm{T}$ & 12,58 & 6.351 & 121 \\
$\mathrm{AD}$ & 16,75 & 8.157 & 164 \\
$10+\mathrm{KP}$ & 16,5 & 8.070 & 163 \\
$20+\mathrm{K}$ & 14,64 & 6.940 & 152 \\
$40+\mathrm{K}$ & 15,93 & 7.951 & 186 \\
\hline
\end{tabular}

T (testemunha), AD (adubação mineral), 10+KP (10 t ha ${ }^{-1}$ de biossólido complementadas com K e P mineral), 20+K (20 t ha ${ }^{-1}$ de biossólido complementadas com $\mathrm{K}$ mineral), $\mathbf{4 0 + K}$ (40 t ha ${ }^{-1}$ de biossólido complementadas com $\mathrm{K}$ mineral).

\section{Estoque de $\mathbf{C}$ e $\mathbf{N}$ no biossólido remanescente}

De acordo com a tabela 4 apenas o biossólido do tratamento $\mathbf{2 0 + K}$, diminuiu sua massa seca em mais de $50 \%$ ao final de cinco anos, chegando à taxa média maior do que $10 \%$ ao ano e igual a $2,42 \mathrm{t} \mathrm{ha}^{-1} \mathrm{ano}^{-1}$.

$\mathrm{Na}$ Tabela 5 observa-se que, proporcionalmente, o $\mathrm{N}$ foi mais liberado do biossólido do que o C. Apesar do tratamento $\mathbf{2 0 + K}$ apresentar a maior porcentagem de liberação de $\mathrm{N}$, nas parcelas do tratamento $\mathbf{4 0 + K}$ houve maior liberação desse elemento em termos quantitativos absolutos.

$\mathrm{O}$ tratamento $\mathbf{4 0 +} \mathbf{K}$ apresentou, proporcionalmente aos outros trata- mentos, maior taxa de decomposição do C orgânico. Esse tratamento foi o que propiciou maior retorno de material orgânico e de N, com a queda de serapilheira durante o processo de reciclagem biogeoquímica (Guedes, 2005).

Considerando o conteúdo de C, observou-se uma taxa de decomposição de $39 \%$ em cinco anos nas parcelas do tratamento $\mathbf{1 0 + K P}$. No tratamento $20+K$ a taxa foi de $60 \%$ e no tratamento $\mathbf{4 0 + K}$ foi de $64 \%$. O modelo de perda de material orgânico foi similar ao de massa total apenas o tratamento $\mathbf{2 0}+\mathbf{K}$. No tratamento $\mathbf{1 0 + K}$ a taxa de perda de massa foi $9 \%$ superior à taxa de decomposição, indicando que, proporcionalmente, perderam-se mais elementos minerais do que C orgânico. 
No tratamento $\mathbf{4 0 + K}$ a taxa de perda de massa foi $23 \%$ menor do que a taxa de decomposição.

\section{Estoque de $\mathrm{C}$ e $\mathrm{N}$ no solo}

A análise de variância mostrou que não houve diferenças significativas entre os tratamentos para os conteúdos totais até $60 \mathrm{~cm}$ de profundidade, tanto para o $\mathrm{C}$ total $(\mathrm{F}=1,3450 ; \mathrm{p}=0,3096)$ quanto para o $\mathrm{N}$ total $(\mathrm{F}=1,2183 ; \mathrm{p}=0,3536)$ e $\mathrm{N}$ mineral $(\mathrm{F}=0,5192 ; \mathrm{p}=0,7218)$. Porém, houve diferenças significativas para o $C(F=3,8220 ; p=0,0315)$ determinado pelo método de Walkley e Black.

Através da figura 4 verifica-se que os valores de $\mathrm{C}$ foram de $41,9 \mathrm{t} \mathrm{ha}^{-1}$ no tratamento $\mathbf{4 0 + K}$ e 39,9 t ha $^{-1}$ no $\mathbf{2 0}+\mathbf{K}$, estatisticamente inferiores aos tratamentos 10+KP $\left(54,8 \mathrm{t} \mathrm{ha}^{-1}\right)$ e $\mathbf{A D}$ $\left(50,7 \mathrm{t} \mathrm{ha}^{-1}\right)$. Esses tratamentos que apresentaram maior conteúdo de $\mathrm{C}$ Walkley e Black, foram os que apresentaram maior desenvolvimento (Guedes, 2005), acúmulo de biomassa (Figura 1) e maior acúmulo de serapilheira sobre o solo (Tabela 3).

\section{DISCUSSÃO}

A biomassa epígea dos eucaliptos aos cinco anos de idade e o $\mathrm{C}$ e $\mathrm{N}$ nela estocados são resultados do desenvolvimento das árvores durante esse período, função, principalmente, da capacidade metabólica de suas folhas realizarem fotossíntese e sintetizarem os compostos orgânicos que constituem os tecidos e a massa de seus componentes. $\mathrm{O} \mathrm{C} \mathrm{e}$ $\mathrm{N}$ são os dois principais nutrientes que constituem a biomassa das árvores. $\mathrm{O}$ C é absorvido diretamente da atmosfera durante o processo fotossintético e o $\mathrm{N}$ é absorvido principalmente do solo através do sistema radicular. A biomassa aérea total dos eucaliptos é dividida nos seguintes componentes: lenho, cascas, galhos e folhas. A estimativa adequada dessa biomassa é fundamental para calcular corretamente os estoques de nutrientes nos eucaliptos, principalmente do componente lenho, que apresenta elevada biomassa e baixos teores de nutrientes.

Analisando a Figura 1, pode-se inferir que todos os outros nutrientes (N, Ca, Mg, B e Zn) que foram colocados com a adubação mineral e que no tratamento $\mathbf{1 0 + K P}$ foram provenientes apenas do biossólido, tiveram suas
Tabela 4 - Porcentagem média $(n=12)$ de perda de massa de biossólido, cinco anos após a aplicação do resíduo, em função da massa remanescente (MR) sobre o solo após esse período

\begin{tabular}{ccc}
\hline Tratamento & MR & \% de perda \\
& & \\
\hline $10+\mathrm{KP}$ & 5.244 & 48 \\
$20+\mathrm{K}$ & 7.931 & 60 \\
$40+\mathrm{K}$ & 23.751 & 41 \\
\hline
\end{tabular}

$\mathbf{1 0 + K P}\left(10 \mathrm{t} \mathrm{ha}^{-1}\right.$ de biossólido complementadas com $\mathrm{K}$ e P mineral), 20+K $\left(20 \mathrm{t}\right.$ ha ${ }^{-1}$ de biossólido complementadas com K mineral), $\mathbf{4 0 + K}$ (40 $\mathrm{tha}^{-1}$ de biossólido complementadas com $\mathrm{K}$ mineral)

Tabela 5 - Conteúdos de carbono orgânico e nitrogênio no biossólido original e médias $(n=12)$ dos conteúdos remanescente nas parcelas de cada tratamento, cinco anos após a aplicação do resíduo. São apresentadas também, em negrito, as respectivas porcentagens de liberação

\begin{tabular}{cccc}
\hline Tratamento & & $\mathrm{C}\left(\mathrm{kg} \mathrm{ha}^{-1}\right)$ & $\mathrm{N}\left(\mathrm{kg} \mathrm{ha}^{-1}\right)$ \\
\hline \multirow{2}{*}{$10+\mathrm{KP}$} & Quantidade na dose aplicada & 1720 & 190 \\
& Quantidade remanescente & 1046 & 76 \\
\multirow{2}{*}{$20+\mathrm{K}$} & Taxa de liberação & $39 \%$ & $60 \%$ \\
& Quantidade na dose aplicada & 3440 & 380 \\
& Quantidade remanescente & 1360 & 75 \\
\multirow{3}{*}{$40+\mathrm{K}$} & Taxa de liberação & $60 \%$ & $80 \%$ \\
& Quantidade na dose aplicada & 6880 & 760 \\
& Quantidade remanescente & 2502 & 182 \\
& Taxa de liberação & $64 \%$ & $76 \%$ \\
\hline
\end{tabular}

$\mathbf{1 0 + K P}$ (10 t ha ${ }^{-1}$ de biossólido complementadas com K e P mineral), 20+K (20 t ha ${ }^{-1}$ de biossólido complementadas com $\mathrm{K}$ mineral), $\mathbf{4 0 + K}$ ( $40 \mathrm{t} \mathrm{ha}^{-1}$ de biossólido complementadas com $\mathrm{K}$ mineral)

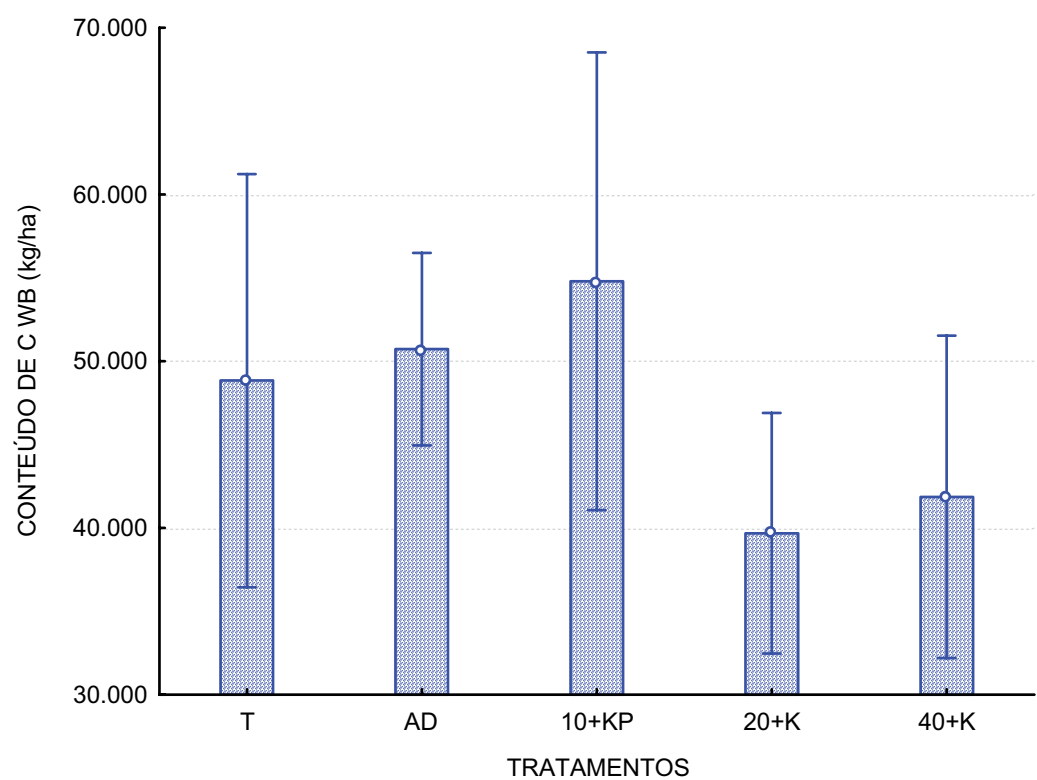

Figura 4 - Efeito dos tratamentos sobre o conteúdo de $C$ Walkley e Black no solo, avaliado até $60 \mathrm{~cm}$ de profundidade, cinco anos após a aplicação de biossólido. São apresentados os valores médios $(n=4)$ e os intervalos de confiança construídos com $95 \%$ de certeza 
demandas atendidas com a aplicação do resíduo. Isso mostra que o biossólido é capaz de suprir as exigências desses nutrientes para o desenvolvimento dos eucaliptos. Esse mesmo comportamento da biomassa total foi verificado também para a biomassa de tronco (lenho+casca), que representa a produção comercial de madeira, já que não houve alterações na partição da biomasssa entre os componentes em função dos tratamentos.

Os valores observados para biomassa epígea de eucalipto estão coerentes com valores encontrados na literatura (Poggiani, 1985; Laclau et al, 2000; Guo et al, 2002, Safou-Matondo et al, 2005), mostrando que o desenvolvimento dos eucaliptos aconteceu dentro do esperado e que foi obtida uma boa produtividade de madeira.

A partição da biomassa total dos eucaliptos entre os componentes não foi alterada pela aplicação de biossólido e/ou fertilizante, sendo que em todos os tratamentos foi mantida a seqüência, lenho $>>>>$ casca $>$ galhos $>$ folhas. Soares et al (2002), ao estimarem a quantidade de carbono presente na parte aérea de eucalipto, encontrou igual seqüência à desse trabalho para o acúmulo de biomassa nos compartimentos.

O compartimento lenho representou aproximadamente $75 \%$ da biomassa aérea dos eucaliptos em todos os tratamentos. Safou-Matondo et al (2005), encontraram valores próximos de $85 \%$ para vários clones de Eucalyptus com 99 meses de idade. As árvores do tratamento $\mathbf{1 0 + K P}$ acumularam, em média, mais biomassa em todos os componentes, tanto nos troncos quanto nas copas. Para as árvores desse tratamento, que apresentaram maior produtivi-dade, a biomassa total de tronco (lenho + casca) acumulada em cinco anos foi de 94,9 $\mathrm{t} \mathrm{ha}^{-1}$, o que resultou em um incremento médio anual (IMA) de $19 \mathrm{t} \mathrm{ha}^{-1} \mathrm{ano}^{-1}$ de madeira com casca. O IMA encontrado na Austrália por Turner e Lambert (2008), para E. grandis com cinco anos, foi de $13 \mathrm{t} \mathrm{ha}^{-1}$ ano $^{-1}$. Santana et al (1999) ao avaliarem três procedências diferentes de $E$. grandis com 6,5 anos em cinco sítios no interior do Estado de São Paulo encontraram valores variando de 95 a $206 \mathrm{t} \mathrm{ha}^{-1}$ de matéria seca de tronco.

Os resultados dos estoques de $\mathrm{Ce}$ $\mathrm{N}$ na biomassa total de eucalipto acima do solo (Figura 2) estão de acordo com os encontrados por Madeira (2002), que, ao estudar as mudanças no estoque de $\mathrm{C}$ em plantações de $E$ globullus mantida sob diferentes disponibilidades de água e nutrientes, verificou que o aumento de $\mathrm{C}$ na plantação de eucalipto foi largamente associado à produção de biomassa.

Apesar de existirem trabalhos que não encontram correlação entre o $\mathrm{C}$ e a biomassa é válido ressaltar que o $\mathrm{C}$ está tão relacionado à mesma, que alguns trabalhos, como o de Schroeder (1992), se baseiam em estimativas de volume e biomassa da árvore para estimar o $\mathrm{C}$ com o intuito de verificar o potencial de árvores em estocar carbono.

O biossólido foi capaz de fornecer $\mathrm{N}$ aos eucaliptos tanto quanto a adubação mineral, confirmando que o resíduo pode ser empregado para o suprimento desse nutriente em plantações florestais.

$\mathrm{O}$ conteúdo de $\mathrm{C}$ na serapilheira acompanhou a variação em sua biomassa. Isso já era esperado, uma vez que esse elemento faz parte da estrutura dos componentes da serapilheira e que não há grandes variações em seus teores. Sendo assim, quanto maior a biomassa de serapilheira, maior será a quantidade de C (tabela 3). Com relação ao $\mathrm{N}$ observa-se que a serapilheira do tratamento $\mathbf{T}$ apresentou menores conteúdos de $\mathrm{N}$ em sua composição (Tabela 3). Isso indica que essa serapilheira das áreas onde não houve entrada de $\mathrm{N}$ e outros nutrientes com a aplicação de fertilizante ou do resíduo é mais lignificada e de difícil decomposição pelos organismos do solo, já que tecidos com maiores teores de $\mathrm{N}$ normalmente são mais tenros e facilitam o processo de desagregação e mineralização do material orgânico. Pode-se inferir a partir disso que a aplicação de biossólido, assim como de fertilizantes minerais, facilita a decomposição da manta florestal acumulada sobre o solo, conforme foi constatado na mesma área experimental, na fase inicial do experimento, por Guedes (2000).

Os resultados para a perda de massa do biossólido encontrados nesse estudo (Tabela 4) estão de acordo com os encontrados por Robinson et al (2002), que avaliaram, anualmente, durante cinco anos, a perda de massa de três tipos de biossólido aplicados superficialmente em uma plantação de Pinus radiata na Austrália e encontraram taxas de degradação variando entre $52 \%$ e $67 \%$ da massa total dos biossólidos ao final de cinco anos.
Mesmo após o contato do biossólido com o solo, com a serapilheira e com as raízes das plantas durante o período de tempo de cinco anos em que o material esteve esparramado no campo; submetido a todas as condiçôes climáticas locais e um intensivo esforço de coletas de variados materiais para vários tipos de estudos, o resíduo apresentou taxa de perda de massa relativamente baixa. Isso mostra que o biossólido alcalino é um material de lenta decomposição, conforme também constatado por Andrade (2004), em condiçōes controladas. Riekerk (1981) também relatou que o biossólido apresenta lenta decomposição e baixas taxas de mineralização, especialmente, quando sob cobertura florestal. Miller (1974) também relatou que o biossólido é um material de difícil decomposição. Esse autor demonstrou que a decomposição não é afetada pela textura e por propriedades químicas do solo, sendo mais dependente da temperatura e da umidade edáficas.

Segundo Guedes (2005), a lenta decomposição do biossólido e conseqüente mineralização dos nutrientes pode ser interessante sob a perspectiva da reciclagem dos nutrientes, pois permite uma sincronia entre liberação e absorção dos elementos pelas árvores, diminuindo as saídas do ecossistema devido à lixiviação. Sob o ponto de vista do manejador, isso pode trazer problemas quando se necessita de uma rápida liberação de nutrientes, como é o caso do P para alimentar o arranque das mudas de eucalipto. Por outro lado, se torna interessante pela perspectiva de liberação de nutrientes durante todo o ciclo da cultura do eucalipto, inclusive durante uma segunda rotação.

Andrade (2004) ressalta que as características dos biossólidos influenciam diretamente em suas taxas de decomposição. Atributos químicos dos biossólidos, como valores excessivamente elevados de $\mathrm{pH}$, teores de metais pesados e sais solúveis conduzem a menores taxas de degradação dos resíduos. Segundo Guedes (2005), além das próprias características bioquímicas do biossólido, o efeito do tamanho das partículas e da área específica em contato com o solo, pode ser importante na taxa de saída de elementos inorgânicos do próprio biossólidoe na determinação da taxa de decomposição do componente orgânico. 
Como os compostos nitrogenados do material orgânico, normalmente, são menos recalcitrantes e são degradados primeiro já era esperado que, proporcionalmente, o $\mathrm{N}$ fosse mais liberado do biossólido do que o C (Tabela 5). Apesar das elevadas taxas de liberação, como o biossólido tinha um alto teor inicial de $\mathrm{N}$, ainda encontra-se com conteúdo capaz de atender as necessidades dos eucaliptos em uma segunda rotação, principalmente, no tratamento $\mathbf{4 0 + K}$ onde foi aplicada a maior dose do resíduo.

Houve maior quantidade de serapilheira depositada sobre o biossólido no tratamento $\mathbf{4 0 + K}$, implicando em manutenção de maior umidade no resíduo devido a maior cobertura da manta florestal. Isso pode ter facilitado a decomposição do biossólido, explicando a maior taxa de decomposição do $\mathrm{C}$ no tratamento 40+K. Além disso, outro fator que pode ter influenciado esse resultado é a proporção de saída de elementos minerais do biossólido.

Com a decomposição e incorporação do biossólido ao solo ao longo do tempo, o material que vai ficando remanescente passa a ter maior recalcitrância, pois vão sobrando os compostos de mais difícil decomposição. Gilmour et al (1996), encontraram que a fração ativa mais lábil do biossólido residual, após sete anos de aplicaçôes de biossólido a cada duas ou quatro semanas, representou de 6 a $10 \%$ do carbono residual total.

Quando se aplicou a maior dose, formou-se uma camada mais espessa e com blocos maiores de biossólido, fato esse que pode ter dificultado a saída de elementos, principalmente o Ca, que já se encontrava no próprio biossólido em sua forma mineral e com teor muito elevado (9\%). A saída direta de elementos inorgânicos do biossólido pode responder por grande proporção da perda de matéria (Robinson et al, 2002).

Andrade (2004), trabalhando na mesma área experimental, também não detectou diferenças significativas entre tratamentos nos conteúdos totais de $\mathrm{Ce}$ $\mathrm{N}$ no solo. $\mathrm{O}$ autor ressalta que se deve ponderar que a simples prática de incorporação ou não do biossólido, afeta os resultados de $\mathrm{C}$ no solo. Quando não há incorporação do resíduo, a amostra de solo para análise é praticamente livre de partículas de biossólido, enquanto que o contrário ocorre quando o material é incorporado. A determinação do teor de
C na amostra, mesmo que por procedimentos menos drásticos de oxidação, como o método clássico de Walkley e Black, é capaz de recuperar parte expressiva do C-orgânico de biossólidos, entre 55 e $70 \%$ e, com isso, o C do resíduo é computado no teor da amostra.

Outros trabalhos na mesma área experimental também não detectaram diferenças significativas entre os tratamentos para os teores totais e minerais de $\mathrm{N}$ no solo (Andrade e Mattiazzo, 2000; Velasco-Molina e Mattiazzo, 2003; Andrade et al, 2005). Apesar das análises de solo não terem mostrado mudanças nos teores de $\mathrm{N}$ no solo, a avaliação das concentrações foliares tem mostrado aumento da disponibilidade do nutriente e maior absorção de $\mathrm{N}$ pelos eucaliptos que receberam o resíduo (Andrade e Mattiazzo, 2000; Rocha, 2002; Guedes \& Poggiani, 2003). Sendo assim, a ausência de efeito significativo para os teores de $\mathrm{N}$ no solo, pode ser reflexo da elevada absorção do $\mathrm{N}$ mineralizado pelas raízes dos eucaliptos que foram tratados com fertilizantes e biossólido em relação ao controle. Como houve maior desenvolvimento e acúmulo de $\mathrm{N}$ nas árvores que receberam tratamentos (Figura 3) em relação à testemunha, deve ter havido maior absorção do $\mathrm{N}$ por essas árvores, diminuindo a quantidade de $\mathrm{N}$ mineral nos solos das parcelas desses tratamentos.

Os maiores valores de $\mathrm{C}$ nos tratamentos 10+KP e AD estão condizentes, uma vez que esses tratamentos que apresentaram maior conteúdo de $\mathrm{C}$ Walkley e Black, foram os que apresentaram maior desenvolvimento (Guedes, 2005), acúmulo de biomassa (Figura 1) e maior acúmulo de serapilheira sobre o solo (Tabela 3). Isso demonstra a maior importância do efeito indireto em relação à própria aplicação do biossólido, para as entradas de material orgânico no sistema. A entrada indireta ocorre devido ao efeito da aplicação de biossólido e de $\mathrm{P}$ mineral sobre o incremento na biomassa aérea dos eucaliptos, biomassa essa que chega ao solo com a deposição de serapilheira por meio da ciclagem biogeoquímica. Segundo Tchienkoua e Zech (2004), a conversão de uso de área para plantação de Eucalyptus grandis pode aumentar o estoque de carbono no solo 2,14 vezes.

As maiores doses, apesar de maior entrada de $\mathrm{C}$ de maneira direta com a aplicação do resíduo, apresentaram valores inferiores de $\mathrm{C}$ no solo (Figura 4) quando determinado pelo método de Walkley e Black. Ressalta-se que isso não foi observado para o $\mathrm{C}$ total determinado pelo auto-analisador. Como o método Walkley e Black é uma digestão química que não recupera todo o $\mathrm{C}$ orgânico do solo, a parte que é extraída e determinada na análise é a fração mais lábil do material. A maior parte da matéria orgânica do biossólido alcalino é recalcitrante e de difícil decomposição, conforme constatado nas baixas taxas de degradação determinadas por Andrade (2004). Assim, as doses maiores devem ter contribuído com maior proporção de matéria orgânica recalcitrante para o solo, carbono esse que deve ter aparecido apenas na determinação do C total pelo autoanalisador.

O monitoramento da fertilidade do solo realizado por Vaz e Gonçalves (2002), no experimento em questão, mostrou que a maioria das doses aplicadas do biossólido não foi efetiva em promover o incremento da matéria orgânica do solo. Durante o primeiro ano após a aplicação do biossólido, aos seis meses, houve redução de $30 \%$ dos teores de matéria orgânica na camada de $0-5 \mathrm{~cm}$ de profundidade, nos tratamentos $\mathbf{2 0 + K}$ e $\mathbf{4 0 + K}$ em comparação com os tratamentos $\mathbf{T}$ e $\mathbf{A D}$. O tratamento $10+K P$ proporcionou, nessa mesma época e camada do solo, o maior teor de $\mathrm{C}$, superando os demais tratamentos. O mesmo padrão de variação observado aos seis meses foi observado também aos treze meses após a aplicação do biossólido (Vaz e Gonçalves, 2002). Aos trinta e dois meses da aplicação das doses do resíduo, nenhuma diferença significativa foi observada entre os tratamentos (Rocha, 2002). A redução inicial dos teores de $\mathrm{C}$ do solo foi atribuída à ocorrência do chamado ou efeito priming (Vaz e Gonçalves, 2002). $\mathrm{O}$ efeito priming teria sido provocado pelo aumento da atividade microbiana, função da presença de compostos facilmente biodegradáveis na $\mathrm{MO}$ do biossólido, que após exaustão, em relativo curto período, induziu a degradação da MO original do solo, como forma de manutenção da elevada ativi-dade microbiana. Outros autores (Terry, 1979; Hsieh et al, 1981; Soares, 2003; Guedes et al, 2006) também observaram a diminuição do carbono do solo com a aplicação de biossólido, relacionando esse fato ao efeito priming. 
É conveniente ressaltar que a diminuição do conteúdo de matéria orgânica no solo não implica apenas em efeitos negativos. Por um lado se o funcionamento do biossólido como condicionador do solo depende do aumento da matéria orgânica no mesmo, por outro lado a decomposição da matéria orgânica é necessária para alimentar os organismos do solo, sendo por meio dela que ocorre o processo de mineralização de nutrientes, melhorando a fertilidade e a qualidade biológica do solo.

A maioria dos trabalhos que relatam aumentos nos teores e conteúdos de $\mathrm{C}$ ou $\mathrm{N}$ no solo com a aplicação de biossólido (Navas et al, 1998; Nyamangara e Mzezewa, 2001; Bhati e Sing, 2003, Silvana et al, 2005, Tarrasón et al, 2008), relatam resultados obtidos em solo onde foi incorporado o resíduo ou em experimentos de incubação. Quando se incorpora o biossólido ao solo é possível que o aumento ocorra somente devido ao "efeito mistura", caracterizado pela junção de dois materiais com características diferentes, cujo valor médio após a mistura vai depender da proporção entre os componentes e da diferença inicial desses materiais. Segundo Guedes (2006), a capacidade do biossólido em promover aumentos no teor de matéria orgânica no solo vai depender, basicamente, das características do próprio resíduo; da dose, da freqüência e da forma de aplicação (incorporação ou distribuição superficial).

\section{CONCLUSÃO}

A aplicação de biossólido tratado com cal, em superfície, não contribui para aumentar a fixação de $\mathrm{C}$ e $\mathrm{N}$ no solo, sendo que o desenvolvimento das árvores é mais importante para propiciar entradas de material orgânico no sistema do que a própria aplicação do biossólido. A aplicação do resíduo incrementa o desenvolvimento de árvores de Eucalyptus grandis e propicia aumentos no acúmulo de biomassa epígea, assim como nos estoques de $\mathrm{C}$ e $\mathrm{N}$ nessa biomassa aérea das árvores, sendo que os troncos respondem pela maior parte do aumento do estoque na vegetação.

\section{REFERÊNCIAS}

ANDRADE, C. A.; MATTIAZZO, M. E. Nitratos e metais pesados no solo e nas árvores após aplicação de biossólido (lodo de esgoto) em plantações florestais de Eucalyptus grandis. Scientia Forestalis, Piracicaba, n.58, p.59-72, dez. 2000.

ANDRADE, C. A. Fração orgânica de biossólido e efeito no estoque de carbono e qualidade da matéria orgânica de um latossolo cultivado com eucalipto. $121 \mathrm{p}$. Tese (Doutorado) - Escola Superior de Agricultura "Luiz de Queiroz", Universidade de São Paulo, Piracicaba. 2004

ANDRADE, C.A., OLIVEIRA, C.; CERRI, C.C. Qualidade da matéria orgânica e estoques de carbono e nitrogênio em Latossolo tratado com biossólido e cultivado com eucalipto. Revista Brasileira de Ciência do Solo, v. 29, p. 803-816, 2005.

BHATI, M.; SING. G. Growth and mineral accumulation in Eucalyptus camaldulensis seedlings irrigated with mixed industrial effluents. Bioresource Technology, v.88, p. 221-228. 2003.

COMPANHIA DE TECNOLOGIA DE SANEAMENTO AMBIENTAL. Aplicação de lodos de sistemas de tratamento biológico em áreas agrícolas - Critérios para projeto e operação. São Paulo, CETESB, 32 p. 1999.

EPA - ENVIRONMENTAL PROTECTION AGENCY OF UNITED STATES. 40 CFR Part 503. Environmental Regulations and Tecnology: Land Application of Municipal Sludge. v.58, n.32, EPA 625/1-83-016: Cincinnati. 178p. 1984.

GILMOUR, J.T.; ROMAN, F.; CLARK, M.D. Decomposition of biosolids in a disposal site soil. Journal of Environmental Quality, v.25, p.1083 -86. 1996.

GUEDES, M.C. Efeito do lodo de esgoto (biossólido) sobre a nutrição, ciclagem de nutrients e crescimento de sub-bosque, em plantação de eucalipto. 74 p. Dissertação (Mestrado) - Escola Superior de Agricultura "Luiz de Queiroz", Universidade de São Paulo, Piracicaba, 2000.

GUEDES, M. C. Ciclagem de nutrientes após aplicação de lodo de esgoto (biossólido) sobre latossolo cultivado com Eucalyptus grandis. 154p. Tese (Doutorado) - Escola Superior de Agricultura "Luiz de Queiroz", Universidade de São Paulo, Piracicaba, 2005.

GUEDES, M.C.; POGGIANI, F. Variação dos teores de nutrientes foliares em eucalipto fertilizado com biossólido. Scientia Forestalis, Piracicaba, n.63, p. 188 - 201. 2003.

GUEDES, M. C. et al. Propriedades químicas do solo e nutrição do eucalipto em função da aplicação de lodo de esgoto. Revista Brasileira de Ciência do Solo, v.30, p.267 - 80. 2006.

GUO, L. B.; SIMS, R. E. H.; HORNE, D. J. Biomass production and nutrient cycling in Eucalyptus short rotation energy forests in New Zealand. I: biomass and nutrient accumulation. Bioresource Technology, v.85, p.273 - 83. 2002.

HSIEH, Y.P.; LOWELL, A.D. \& MOTTO, H.M. Modeling sewage sludge decomposition in soil: I. organic carbon transformation. Journal of Environmental Quality, v.10, p.54-64. 1981.

LACLAU, J. P; BOUILLET, J. P.; RANGER, J. Dynamics of biomass and nutrient accumulation in a clonal plantation of Eucalyptus in Congo. Forest Ecology and Management, v.128, p. 181 - 196. 2000.

MADEIRA, M. V. et al. Changes in carbon stocks in Eucalyptus globulus Labill. Plantations induced by different water and nutrient availability. Forest Ecology and Management, v.171, p.75 $-85.2002$.

MILLER, R. H. Factors Affecting the Decomposition of an Anaerobically Digested Sewage Sludge in Soil. Journal of Environmental Quality, v. 3, p. 376-380, 1974

NAVAS, A.; BERMUDEZ, F.; MACHIN, J. Influence of sewage sludge application on physical and chemical properties of Gypsisols. Geoderma, v. 87 , p. $123-135,1998$.

NYAMANGARA, J.; MZEZEWA, J. Effect of long-term application of sewage sludge to a grazed grass pasture on organic carbon and nutrients of a clay soil in Zimbabwe. Nutrient Cycling in Agroecosystems, v.59, p. 13-18. 2001

POGGIANI, F. Ciclagem de nutrientes em ecossistemas de plantaçôes florestais de Eucalyptus e Pinus. Implicaçôes silviculturais. 211p. Tese (Livre Docência) - Escola Superior de Agricultura "Luiz de Queiroz", Universidade de São Paulo, Piracicaba, 1985.

RIEKERK, H. Effects of sludge disposal on drainage solutions of two forest soils. Forest Science, v.27, n.4, p.792-800. 1981.

ROBINSON, M. B.; POGLASE, P. J.; WESTON, C. J. Loss of mass and nitrogen from biosolids applied to pine plantation. Australian Journal of Soil Science, v.40, n.40, p.1027 - 39. 2002.

ROCHA, G.N. Monitoramento da fertilidade do solo, nutrição mineral e crescimento de um povoamento de Eucalyptus' grandis fertilizado com biossólido. 48p. Dissertação (Mestrado) - Escola Superior de Agricultura "Luiz de Queiroz", Universidade de São Paulo, Piracicaba, 2002.

SAFOU-MATONDO, R. et al. Hybrid and clonal variability of nutrient content and nutrient use efficiency in Eucalyptus stands in Congo. Forest Ecology and Management, v. 210, p. 193-204, 2005.

SANTANA, R. C.; BARROS, N. F.; NEVES, J. C. L. Biomassa e conteúdo de nutrientes de procedências de Eucalyptus grandis e Eucalyptus saligna em alguns sitios florestais do Estado de São Paulo. Scientia Forestalis, v.56, n.155 - 69. 1999.

SCHROEDER, P. Carbon storage potencial of short rotation tropical tree plantations. Forest Ecology and Management, v. 50, p. $31-41.1992$.

SILVANA, A.P.F. et al. Sewage sludge effects on gas fluxes at the soil-atmosphere interface, on soil $\partial^{13} \mathrm{C}$ and on total soil carbon and nitrogen. Geoderma, v. 125 , p. $49-57,2005$

SOARES, M.T.S. Taxas de mineralização e de lixiviação do nitrogênio, e alteraçōes da fertilidade de um Latossolo Vermelho-Amarelo degradado e outro não-degradado fertilizados com biossólido e florestados com Eucalyptus grandis. 142p. Tese (doutorado). Piracicaba, Escola Superior de Agricultura "Luiz de Queiroz", Universidade de São Paulo. 2003.

SOARES, C. P. B.; OLIVEIRA, M. L. R. Equaçōes para estimar a quantidade de carbono na parte aérea de árvores de eucalipto em Viçosa, Minas Gerais. Revista Árvore, Viçosa, v.26, n.5, p.533 - 39. 2002.

TARRASÓN, D. et al. Differences on nitrogen availability in a soil amended with fresh, composted and thermally-dried sewage sludge. Bioresource Technology, v. 99, p. 252-259, 2008. 
TCHIENKOUA M.; ZECH W. Organic carbon and plant nutrient dynamics under three land uses in the highlands of West Cameroon. Agriculture, Ecosystems and Environment, v. 104 p. 673-679, 2004.

TERRY, R.E.; NELSON, D.W. \& SOMMERS, L.E. Carbon cycling during sewage sludge decomposition in soils. Soil Science Management Journal, v.43, p. 494-499. 1979.

TSUTYA, M. T. Alternativas de disposição final de biossólidos gerados em estaçôes de tratamento de esgoto. In: BETIOL, W.; CAMARGO, O. A. Impacto ambiental do uso agrícola do lodo de esgoto. Jagauriúna: São Paulo. EMBRAPA Meio Ambiente. Cap.4, p.69 - 105. 2000.

TURNER, J.; LAMBERT, M.J. Nutrient cycling in age sequences of two Eucalyptus plantation species. Forest Ecology and Management, in press. 2008:

VAZ, L. S. V. Crescimento inicial, fertilidade do solo e nutriçāo de um povoamento de Eucalyptus grandis fertilizado com biossólido. 41 p. Dissertação (Mestrado) - Escola Superior de Agricultura "Luiz de Queiroz", Universidade de São Paulo, Piracicaba, 2000.

VAZ, L. M. S; GONCALVES, J. L. M. Uso de biossólidos em povoamento de eucalipto: efeito em atributos químicos do solo, no crescimento e na absorção de nutrientes. Revista Brasileira de Ciência do Solo, v.26, n.3, p.747 - 758. 2002.

VELASCO-MOLINA, M. Nitrogênio e metais pesados em latossolo e eucalipto cinquienta e cinco meses após a aplicação de biossólido. 66p. Dissertação (Mestrado) - Escola Superior de Agricultura "Luiz de Queiroz", Universidade de São Paulo, Piracicaba, 2004.

\section{Endereço para correspondência:}

Ana Cláudia Silva de Lira

Universidade do Estado do Amapá Av. Presidente Getúlio Vargas, 650 Centro

68906- 970 Amapá - AP - Brasil E-mail: asclira@ueap.ap.gov.br 